\title{
AGUARDIENTE Y VIÑAS EN CHILE: QUILLOTA, COLCHAGUA Y CAUQUENES EN EL PADRÓN DE 1777
}

\author{
Brandy and Vineyards in Chile: Quillota, Colchagua y Cauquenes from 1777 census
}

\author{
Pablo Lacoste* \\ Juan Guillermo Muńoz** \\ Amalia Castro ${ }^{* * *}$
}

\section{RESUMEN}

El artículo estudia la elaboración de aguardiente en la Zona Central de Chile, en los corregimientos de Quillota, Colchagua y Cauquenes a partir del padrón de 1777. Se detecta una cultura de elaboración de aguardiente a partir de borras y orujo en la Zona Central de Chile. Ello implica una clara diferencia con las prácticas vigentes en el Norte de Chile, donde se elaboraba aguardiente a partir del vino (pisco). Esta actividad no estaba concentrada sino distribuida entre muchos pequeńos productores. Era una actividad transversal a distintos sectores sociales: distinguidos nobles y audaces comerciantes; ricos hacendados y campesinos pobres.

Palabras clave: Viticultura, aguardiente, agroindustria.

\footnotetext{
* Instituto de Estudios Avanzados, Universidad de Santiago de Chile. Santiago, Chile. Correo electrónico: pablo.lacoste@usach.cl

** Instituto de Historia, Facultad de Humanidades, Universidad de Santiago de Chile. Santiago, Chile. Correo electrónico: juan.muñoz.c@usach.cl

*** Escuela de Historia, Facultad de Comunicaciones y Humanidades, Universidad Finis Terrae. Santiago, Chile. Correo electrónico:castrosancarlos@yahoo.com.mx
}

Artículo recibido el 21 de octubre de 2013. Aceptado el 7 de mayo de 2014. 


\begin{abstract}
The article examines the production of brandy in central Chile, in the districts of Quillota, Colchagua and Cauquenes from 1777 census. Culture is detected production of spirits from lees and pomace in central Chile. This implies a clear difference with current practice in northern Chile, which was produced from wine brandy (pisco). This activity was not concentrated but distributed among many small producers. It was a cross-cutting activity to different social sectors distinguished nobles and merchants bold, rich landowners and poor peasants.
\end{abstract}

Keywords: Viticulture, brandy, agrobusiness.

El aguardiente alcanzó singular relevancia en los pueblos de Europa y América. En Europa, el siglo XVI marcó el nacimiento del aguardiente y el alcohol; el XVII presenció su desarrollo y el XVIII su divulgación (Braudel, 1994: 27). Con el tiempo se desarrollaron denominaciones de origen de aguardiente de uva, tanto en Francia (Cognac, Armagnac) como en Portugal (Oporto) y España (Brandy de Jerez) (Cuevas, 2003; Bennet, 2005). En América Latina también se desarrolló una importante producción de aguardiente en México (Tequila), Perú (Huertas, 2004 y 2012; Price, 2012) y Chile (Cortés, 2006).

Dentro de Chile, la tradición de la elaboración de aguardientes culminó con la delimitación de la Denominación de Origen Pisco (1931). A partir de entonces, Chile consolidó jurídicamente la protección del aguardiente de vino. De esta manera se sentaron las bases para consolidar el Pisco como la principal Denominación de Origen de América del Sur y la segunda de América Latina después del Tequila. Lo singular del Pisco es que se trata de una Denominación de Origen disputada por dos países: Chile y Perú.

Desde el punto de vista de la historia, se nota una notable asimetría entre los estudios realizados en Perú con los trabajos localizados en Chile. En Perú, la historiografía ha realizado una obra de considerable envergadura (Huertas, 2004, 2012; Rice, 2012). En cambio en el caso chileno, apenas se han realizado algunos trabajos acotados (Cortés, 2006). En ese sentido, resulta oportuno profundizar los estudios sobre la destilación de aguardiente en Chile.

El padrón de 1777 es una buena fuente para abordar el tema. Fue impulsado por la corona para incrementar la recaudación fiscal. En el Archivo Nacional de Santiago de Chile se conservan los registros de los corregimientos de Quillota, Colchagua y Cauquenes. Este censo registró la presencia de 353 viñas en estos partidos, en las cuales se elaboraban 912 arrobas de aguardiente (1 arroba, @ = 36 litros, exactamente 35,552 litros). Los documentos permiten detectar algunas características relevantes de esta actividad. 


\section{PAISAJES DE QUILLOTA, COLCHAGUA Y CAUQUENES}

El surgimiento de las ciudades de estas circunscripciones fue un fenómeno atípico dentro de la tradición española en América, en general, y en Chile, en particular. Por lo general las ciudades chilenas como Santiago, Concepción, Mendoza, San Juan o La Serena, se fundaron en territorios hasta entonces deshabitados de europeos. En cambio las villas de estos tres corregimientos surgieron en espacios poblados por campesinos españoles (peninsulares o americanos). En vez de surgir como un enclave de avanzada en tierras ajenas a la cultura hispana, estas ciudades emergieron como un intento de organizar y disciplinar a la población dispersa que ya estaba allí, cultivando la tierra y criando ganados, como principal actividad económica. El incremento de la producción de alimentos y demás bienes, generó las condiciones para el aumento de la población rural. Debemos recordar que, salvo el caso excepcional de Quillota (1717), todavía no existía ninguna villa ni ciudad en estos corregimientos hasta mediados la década de 1740, recién entonces comenzó el proceso fundacional.

El corregimiento de Quillota se hallaba en el norte del Valle Central, al oeste de la Cordillera de la Costa, aislada físicamente (por ríos y montañas que formaban sus límites ${ }^{1}$ ) de las ciudades de su entorno, lo que significó, desde un comienzo, una barrera complicada para el transporte. Tras la conquista comenzó la colonización y el mestizaje. Las primeras ciudades del corregimiento surgieron en el siglo XVIII: Quillota (1717), Casablanca (1753), Petorca (1753), La Ligua (1754) e Illapel (1754). Su poblamiento fue lento debido a la oposición de los grandes hacendados, que no deseaban compartir su poder omnímodo con autoridades municipales. Para la fecha del empadronamiento, la población de esta provincia superaba los 23.500 habitantes, incluyendo 18.000 espańoles, 3.500 indios y 2.000 negros y mulatos ${ }^{2}$. En el siglo XVII la hacienda se consolidó en la zona gracias a la actividad agrícola y ganadera ${ }^{3}$. Como resultado de la acción hacendal y la fertilidad del territorio, la población estaba dispersa por las tierras de esta jurisdicción.

$\mathrm{Al}$ sur del Maule se encontraba el corregimiento de Cauquenes, creado en $1769^{4}$. La principal ciudad de este corregimiento fue Nuestra Señora de las

\footnotetext{
${ }^{1}$ Su límite norte estaba formado por los ríos Choapa e Illapel que lo separaban del corregimiento de Coquimbo. Por el sur, el valle de Casablanca y la cuesta de Lo Prado la separaban del corregimiento de Melipilla. Limitaba al oeste con la jurisdicción de Valparaíso y el Océano Pacífico (la estancia de Quintero estaba dentro de la jurisdicción de Quillota). El límite este estaba en la Cordillera de la Costa que separaba al corregimiento de Quillota del Combarbalá por el nordeste, del valle del Aconcagua en el centro-este y de la ciudad de Santiago en el centro-sur.

${ }^{2}$ Cobos (1989: 50-51).

${ }^{3}$ Mellafe y Salinas (1988: 97).

${ }^{4}$ Este se extendía de cordillera a mar, teniendo como límite norte el río Maule hasta tocar el Longaví y el estero de La Raya, afluente del Itata.
} 
Mercedes de Manso del Tutubén, que acabó por tomar el nombre del partido (1742), seguida de San Antonio de la Florida o Huerta de Maule (1754) y San Javier (1755). Hacia 1772 la población de este corregimiento ascendía a 15.000 personas. De acuerdo a las descripciones de la época, Cauquenes poseía buenas tierras y condiciones para la agricultura, sobre todo viñedos, sumando otros tipos de explotación (maderera, pesquera y minera) aunque su desarrollo se encontraba frenado por las distancias, el alto costo del transporte y el bajo precio de los productos agropecuarios comercializables ${ }^{5}$. Al igual que Quillota y Colchagua, su carácter era rural. En los tres corregimientos, la población se arraigó en el campo, a pesar de los esfuerzos de la autoridad por asentarlos en villas y ciudades. Por ello, lo importante era lo que sucedía en las parcelas agropecuarias, grandes y pequeñas, que se hallaban distribuidas a lo largo del territorio.

De este modo, los registros documentaron tres corregimientos rurales al comenzar el último cuarto del siglo XVIII que las autoridades supusieron factibles de aportar al erario si se ponía un impuesto al aguardiente: Quillota (23.000 habitantes), Colchagua (14.000) y Cauquenes (15.000). Los tres tenían en común un aislamiento relativo de sus ciudades vecinas producto de las malas condiciones para el transporte y las comunicaciones: montańas, grandes ríos y falta de caminos (inclusive en el siglo XVIII) hicieron de los intercambios a lomo de mula unas de las pocas alternativas viables. Por ejemplo, para llegar de Quillota a Santiago, era necesario atravesar la Cordillera de la Costa por la cuesta La Dormida, lo cual exigía trepar a más de 1200 metros de altitud para llegar a la hacienda de Til Til y de allí, avanzar hacia Santiago a través de algunas lomas menores.

Los recursos hídricos tuvieron un papel de especial importancia como organizadores de la actividad socioeconómica, ya que ordenaron los asentamientos y generaron espacios fértiles para el desarrollo, operando como auténticos oasis verdes en zonas predominantemente áridas. Para el transporte, se construyeron puentes colgantes en el siglo XVI sobre los ríos Maipo y Cachapoal ${ }^{6}$. Más al sur, en vez de puentes, se organizó un sistema de balsas de piel de lobo, lo cual encarecía el transporte, porque no solo había que pagar los costos del servicio de los balseros, sino también los derechos que exigían los cabildos. En los ríos interjurisdiccionales había doble imposición. Así, por ejemplo, para cruzar el río Maule, había que pagar tributos tanto al Cabildo de Talca como al Cabildo de Cauquenes. Mientras los arrieros enlazaban estos corregimientos con los mercados del norte y el sur, las barcas y lanchones prestaban un servicio de transporte por los ríos Aconcagua, Cachapoal, Tinguiririca, Loncomilla y Maule, en dirección al oeste para desembocar en pequeños puertos como Concón y Nueva Bilbao de Gardoquí,

\footnotetext{
${ }^{5}$ Cobos (1989: 80-81).

${ }^{6}$ Drago Rojas (1994: I, 15).
} 
actual Constitución, sobre el Océano Pacífico; y desde allí los barcos de alta mar completaban el transporte hacia los puertos de Talcahuano, en el sur, y Valparaíso, en el norte. A pesar de estas dificultades, los campesinos de estas localidades se propusieron cultivar las vińas y elaborar vinos y aguardientes, apuntando sobre todo, a mercados secundarios, como los yacimientos mineros. El presente artículo procura dimensionar esos trabajos.

Cabe advertir que en el resto de los corregimientos la indagatoria sobre la producción de aguardientes fue un fracaso, así el 19 de julio de 1779 el administrador general de real aduana le escribía al gobernador que en Melipilla, Aconcagua, Rere, Itata, y Concepción no se había cumplido, y que los informes de Rancagua estaban sin oficio, firma, ni autorización alguna. De hecho para la Villa de Santa Cruz de Triana y sus chácaras solo se anotó el vino que se cosechaba anualmente, y no el aguardiente, con 14 sujetos y 675 arrobas. En El Mostazal, en cambio, se consideraron ambos productos, anotándose diez vińateros con 1260 arrobas de vino y 38 de aguardiente, lo que se contradice en los testamentos e inventarios de la época ${ }^{7}$.

La industria vitivinícola de estos partidos del Valle Central se hallaba fuertemente condicionada por la falta de carreteras. Si se compara, por ejemplo, con Cuyo, las diferencias son notables. En principio, las viñas del Valle Central tenían la ventaja de mayor cercanía a los mercados que los cuyanos. Las haciendas vallecentralinas estaban -como máximo- a $250 \mathrm{~km}$ de Santiago o Concepción, mientras que los viticultores cuyanos estaban a más de $1.000 \mathrm{~km}$ de Buenos Aires. Pero esta ventaja quedaba neutralizada por los accidentes geográficos: los cuyanos llegaban fácilmente a Buenos Aires con sus carretas, a través de las planicies pampeanas. El tráfico comenzó en el siglo XVII, y maduró en la centuria siguiente. Hacia fines del XVIII, cada año salían 700 carretas de Mendoza, cargadas mayoritariamente con botijas de vino, rumbo a los mercados rioplatenses. En Mendoza los troperos formaron un gremio poderoso y próspero, que dinamizó la economía y lideró el proceso de surgimiento de una protoburguesía regional ${ }^{8}$. En cambio, este sistema no existía en el Maule ni en Quillota; la Cordillera de la Costa y los ríos tan caudalosos como el Maipo, el Cachapoal, el Tinguiririca, Maule y el Loncomilla, entre otros, juntamente con las ondulaciones del terreno, impedían la circulación de carretas en largas distancias, a menos que se construyeran costosos puentes y otras obras de arte. El primer camino importante para carretas en Chile fue el que construyó don Ambrosio O’Higgins entre Santiago y Valparaíso a fines del siglo XVIII'.

\footnotetext{
${ }^{7}$ Archivo Nacional de Chile (AN), Fondo Capitanía General (FCG), 353, 155 a 158.

${ }^{8}$ Lacoste (2005 a y b).

${ }^{9}$ Pinto, 1976.
} 


\section{EL PADRÓN DE 1777 EN LOS TRES CORREGIMIENTOS: DE VIŃAS Y AGUARDIENTES}

El censo de viñas y aguardientes se organizó desde el poder en 1777. El mecanismo fue usado en los distintos corregimientos. El objetivo era levantar un "padrón de todas las viñas contenidas en su jurisdicción, recibiendo juramento de sus dueños sobre las arrobas de aguardiente que cosechan y venden todos los años, dando cuentas a este superior gobierno", según expresaba el corregidor de Quillota, don Feliciano José Lethelier, en carta al teniente de Illapel, fechada en 17 de diciembre de ese año ${ }^{10}$. Después de un año de realizar los relevamientos, los tenientes (encargados del trabajo en terreno con los viticultores) remitieron los registros a sus respectivos corregidores. Sobre la base de estos documentos se levantó el Padrón.

En total se detectaron 353 viñas, que elaboraban 912 arrobas de aguardiente al año. La mayor cantidad se detectó en Colchagua (190 viñas y 533,6 arrobas de aguardiente), seguida por Quillota (96 viñas con 293 arrobas). Menor desarrollo tenía Cauquenes (67 viñas con 85,75 arrobas). Uno de los datos relevantes es el alto porcentaje de vińas dedicadas a elaborar aguardiente: 323 (90\%). Muy pocas viñas se abstenían de este tipo de tareas (30). La mayor tendencia hacia el aguardiente se registraba en Colchagua, donde el $98 \%$ de las viñas lo elaboraban; en los otros dos corregimientos también se verificaban estas prácticas, aunque en menor proporción (86\% en Quillota y 79\% en Cauquenes). La fuente no indica la superficie cultivada con esas viñas ni la cantidad de plantas. Tampoco entrega datos sobre la cantidad de vino elaborado. Solo se menciona la existencia de cada vińa, y la cantidad de aguardiente elaborado en cada una.

El cruce de la producción con la población entrega datos de interés. Sobre todo por el notable liderazgo de Colchagua: a pesar de tener solo el $27 \%$ de la población del grupo, cultivaba el $54 \%$ de las viñas y elaboraba el $58 \%$ del aguardiente. Colchagua casi duplicaba en producción a Quillota, cuando este corregimiento casi lo doblaba en población. En efecto, Quillota poseía el 44\% de población, cultivaba el $27 \%$ de las vińas y elaboraba el $32 \%$ del aguardiente. Por su parte, Cauquenes también superaba a Colchagua en población (15.000 habitantes sobre 14.000); pero cultivaba un tercio de sus viñas (19\%) y elaboraba apenas un sexto de su aguardiente (9\%).

Las viñas de estos distritos estaban orientadas fundamentalmente a elaboración de vino. Después de la vendimia, se realizaba la pisada de la uva y, con el mosto obtenido, se iniciaba la fermentación para conseguir así el vino. El aguardiente, en cambio, era una actividad secundaria. Coincidiendo con Cortés ${ }^{11}$

\footnotetext{
${ }^{10}$ AN, FCG, 353, 124.

${ }^{11}$ Cortés (2005: 49).
} 
para ello se usaba el "borujo", es decir, el hollejo y los restos de jugo de uva restantes después de la primera pisada. En Perú, en cambio, al parecer este destilado se fabricaba a partir del mosto ${ }^{12}$. Esta era una actividad complementaria pero importante dentro del sistema vitivinícola regional. La naturaleza del equipamiento de lagares y prensa facilitaba estas tendencias, dado que "por su poca fuerza, debe necesariamente dejar mucho jugo en los orujos; por ese motivo se pone otra vez en el lagar para volverlo a pisar o bien, se destina directamente a destilación y, como producen mucho aguardiente, esto compensa en algo la imperfección de la prensa. Se calcula, en muchas partes, que este segundo producto costea todos los gastos de cultivo, vendimia y fabricación del vino"13.

La documentación del Padrón permite inferir que el aguardiente elaborado en estos corregimientos, corresponde a este método. Las instrucciones de los corregidores a sus lugartenientes señalaban, concretamente, que debían tomar declaración jurada a los dueños de vińas para que "bajo dicho juramento declaren el aguardiente que cosechan de orujos y borras", según informa don Pedro Carvallo, en El Olivar el 20 de diciembre de $1777^{14}$. Y este fue, justamente, el criterio que se tuvo en cuenta para elaborar los informes. Así, por ejemplo, don José de Avaria, arrendatario de la hacienda de Choapa, en Illapel, al norte del corregimiento de Quillota, declaró bajo juramento que esa propiedad "produciría 70 arrobas de aguardiente, poco más o menos, entre borras y orujo", informa don Cristóbal Miranda, teniente de alcalde mayor de minas y de justicia del asiento de Illapel, el 17 de diciembre de $1777^{15}$. Por su parte, el capitán don Manuel de Valdovinos Salinas, lugarteniente del corregidor en Malloa, elevó su informe el 13 de noviembre de 1777, señalando explícitamente, junto a cada viticultor, la cantidad de aguardiente que "entre borras y borujos sacará" ${ }^{16}$. Lo mismo ocurría a la inversa: cuando un viticultor no elaboraba aguardiente a partir de estos materiales, la documentación lo indicaba. Por ejemplo, en la misma doctrina de Malloa, se informa que don Gabriel de Duñabeytia "no saca aguardiente de los borujos que solo sacará de las borras" ${ }^{17}$. Esta práctica de elaborar aguardiente a partir de orujos y borras se extendió en la Zona Central de Chile, hasta consolidarse en el siglo XVIII y mantenerse aún con fuerza en el XIX.

De estos datos, lo primero que se observa es la notable cantidad de viticultores. En una población todavía reducida y dispersa, resulta considerable

\footnotetext{
${ }^{12}$ Huerta Vallejos (2004: 53).

${ }^{13}$ Gay (1855: 191).

${ }^{14}$ AN, FCG, 353, 135.

${ }^{15}$ AN, FCG, 353, 120.

${ }^{16}$ AN, FCG, 353, 132.

${ }^{17}$ AN, FCG, 353, 133.
} 
la cantidad de vińas que había. Esta situación contrasta con algunas visiones que se habían construido sobre la propiedad en Chile, tradicionalmente atribuida a grandes haciendas. El censo revela una co-existencia del modelo de grandes latifundios, organizados en haciendas, con pequeñas propiedades agroindustriales, centradas en la vid y el vino. En otras palabras, junto con el gran hacendado, que orientaba sus recursos a la agricultura y la ganadería (actividades primarias), venía surgiendo una pequeña burguesía que, a partir de la vid y el vino, estaba echando las bases de un incipiente desarrollo industrial en Chile.

El registro de la provincia de Quillota se realizó teniendo en cuenta sus ocho doctrinas. La mayor producción de esta provincia se hallaba en las doctrinas de Quillota y Limache, en el corazón del Valle Central, unos $100 \mathrm{~km}$ al nordeste de Santiago. En esas dos localidades se cultivaban 80 viñas y se elaboraban 176 arrobas de aguardiente. En total, Quillota agrupaba 92 viñas, con una producción de 275 arrobas 72 cuartillos.

En el corregimiento de Colchagua, se percibían tres grupos de lugares, algunos coincidentes con doctrinas, claramente diferenciadas. Por un lado estaban los distritos de clara vocación vitivinícola, como Chimbarongo (34 viñas), Río Claro (29), Teno (25), Nancagua (19), Malloa (18) y la villa de San Fernando (17). En un nivel intermedio se encontraban Coinco ( $\left.11^{18}\right)$ Colchagua (10 vińas), Tutuquén (10) y Candelaria (ocho). Las de menor incidencia vitivinícola eran Estrella (seis), Taguataguas y Guacargüe (cinco cada una) Pichidegua (cuatro), Olivar (tres), Lolol y Navidad (dos viñas cada una), En su conjunto, en Colchagua había 208 vińas con una producción de 541 arrobas y 23 cuartillos.

El partido de Cauquenes fue también registrado en el censo. A diferencia de los de Quillota y Colchagua, no se entregan datos discriminados por doctrina. Pero aparecen otras informaciones relevantes. Por ejemplo, al final de su informe al gobernador del 17 de diciembre de 1777, don Bernardo López, corregidor de Cauquenes, añadió: "Agréguese a esta suma la cantidad de una arroba y un cuarto que en el numero de 15 sujetos pobres (ilegible) viñas se cosechan los que no van nominados para no aumentar este padrón” ${ }^{19}$. Esta referencia muestra el desdén del corregidor por los pequeños viticultores, que apenas cultivaban pocas plantas de vińa. Al parecer, sus nombres no merecían figurar en un padrón oficial. Agrupaba 67 vińas que producían 89 arrobas y cuatro cuartillos.

Si bien las cifras pueden mostrar la producción aguardentera como algo marginal, era relevante por la utilidad que brindaba: los productores de vino debían fabricarlo para satisfacer los gustos de sus consumidores, que preferían vinos con alto grado alcohólico. Al agregar aguardiente se elevaba el espíritu de los vinos

\footnotetext{
${ }^{18}$ Son 12 en el detalle de las visitas.

${ }^{19}$ AN, FCG, 353, 127.
} 
flojos, alargaba el período de conservación del vino y mantenía el precio alto ${ }^{20}$. Los datos mostrados hasta ahora han permitido una primera interpretación de las fuentes, sobre todo en el sentido de identificar la situación espacial de estas viñas. Estas fuentes hacen visible la amplia dispersión que alcanzó la viticultura en las zonas periféricas de Chile en el siglo XVIII, como así también, la práctica de aprovechar los orujos y borras para elaborar aguardiente. Estos elementos ya tienen un significado de interés. Pero hay más.

\section{VITICULTURA Y AGROINDUSTRIA DEL DESTILADO: ACTIVIDADES ECONÓMICAS DESCONCENTRADAS}

Uno de los problemas actuales de la industria de las bebidas en Chile se encuentra en la tendencia a la concentración de la actividad en un reducido número de propietarios que controlan los mercados en forma oligopólica. Tanto la cerveza como el vino son industrias signadas por la fuerte concentración: solo tres empresas controlan más del $80 \%$ del mercado en ambas actividades. Estas posiciones dominantes generan una serie de problemas y distorsiones, de fuerte impacto regresivo en la actividad social, económica y cultural del país. Con estas inquietudes, conviene examinar lo que ocurría en el siglo XVIII. ¿¿En qué medida la viticultura y elaboración de aguardiente estaba entonces concentrada en un pequeño número de hacendados?

El diseño del Padrón permite conocer el nivel de concentración de la propiedad vitivinícola. Porque el corregidor, al impartir las instrucciones a sus lugartenientes, solicitó, precisamente, convocar a los propietarios de vińas, uno por uno, para que pudieran dar cuenta de sus propiedades. En ese sentido, cada registro corresponde a un propietario diferente.

El Padrón detectó la presencia de las haciendas y su gran capacidad productiva. Fue el caso de la hacienda de Choapa, ella sola producía 70 arrobas de aguardiente, lo cual equivale, por lo menos, a 3500 plantas de vińa solo para este fin. El procedimiento se utilizó en todas las doctrinas de los tres corregimientos, con lo cual, se pudo identificar no solo la cantidad de vińas, sino también los propietarios y su capacidad productiva. Con ello, se trata de identificar el nivel de concentración (o desconcentración) que tenía la viticultura en Chile en el siglo XVIII. En ese sentido, los documentos muestran la existencia de una gran distribución de las viñas entre diversos propietarios.

A partir del volumen de producción, se definieron cuatro categorías de aguardenteros: micro, pequeños, medianos y grandes. El microproductor elaboraba

${ }^{20}$ Cortés (2005: 62). 
menos de tres arrobas de aguardiente por año. Los pequeños productores destilaban de tres a diez arrobas por cosecha; los medianos elaboraban entre 11 y 26 arrobas, mientras que los grandes superaban las 50. Para examinar el tema en detalle se han elaborado el Cuadro I y el Cuadro II.

\section{Cuadro I}

Cantidad de productores de aguardiente (agrupados por tamaño) Corregimientos de Quillota, Cauquenes y Colchagua (1777)

\begin{tabular}{|l|l|l|l|l|l|l|l|l|l|}
\hline & \multicolumn{2}{|l|}{ Quillota } & \multicolumn{2}{l|}{ Cauquenes } & \multicolumn{2}{l|}{ Colchagua } & \multicolumn{2}{l|}{ Total } \\
\hline & Productores & $\%$ & Productores & $\%$ & Productores & $\%$ & Productores & $\%$ \\
\hline $\begin{array}{l}\text { Micro } \\
-3 @\end{array}$ & 48 & $58 \%$ & 45 & $85 \%$ & 153 & $82 \%$ & 246 & $76 \%$ \\
\hline $\begin{array}{l}\text { Pequeńa } \\
3-10 @\end{array}$ & 29 & $35 \%$ & 8 & $15 \%$ & 22 & $11 \%$ & 59 & $18 \%$ \\
\hline $\begin{array}{l}\text { Mediana } \\
11-26 @\end{array}$ & 5 & $6 \%$ & - & - & 12 & $6 \%$ & 17 & $5 \%$ \\
\hline $\begin{array}{l}\text { Grande } \\
70 \text { @ }\end{array}$ & 1 & $1 \%$ & - & - & - & - & 1 & & $0,3 \%$ \\
\hline Total & $\mathbf{8 3}$ & $\mathbf{1 0 0}$ & $\mathbf{5 3}$ & $\mathbf{1 0 0}$ & $\mathbf{1 8 7}$ & $\mathbf{1 0 0}$ & $\mathbf{3 2 3}$ & $\mathbf{1 0 0}$ \\
\hline
\end{tabular}

Fuente: Elaboración propia a partir del padrón de viñas de 1777. Archivo Nacional de Chile, Capitanía General, volumen 353, fojas 119-158.

\section{Cuadro II}

Tamaños y producción: Auge de la pequeña propiedad

\begin{tabular}{|c|c|c|c|c|c|c|c|c|}
\hline & \multicolumn{2}{|l|}{ Quillota } & \multicolumn{2}{|c|}{ Cauquenes } & \multicolumn{2}{|c|}{ Colchagua } & \multicolumn{2}{|l|}{ Total } \\
\hline & @ Agte & $\%$ & @ Agte & $\%$ & @ Agte & $\%$ & @ Agte & $\%$ \\
\hline $\begin{array}{l}\text { Micro } \\
-3 @\end{array}$ & 65 & $22 \%$ & 43,50 & $50,7 \%$ & 206,5 & $38 \%$ & 315,0 & $34,5 \%$ \\
\hline $\begin{array}{l}\text { Pequeña } \\
3-10 @\end{array}$ & 134 & $45 \%$ & 42,25 & $49,2 \%$ & 144,1 & $27 \%$ & 320,35 & $35 \%$ \\
\hline $\begin{array}{l}\text { Mediana } \\
11-26 @\end{array}$ & 24 & $8 \%$ & - & - & 183,0 & $34 \%$ & 207,0 & $22 \%$ \\
\hline $\begin{array}{l}\text { Grande } \\
70 \text { o + }\end{array}$ & 70 & $24 \%$ & - & - & - & - & 70,0 & $7 \%$ \\
\hline Total & 293 & 100 & 85,75 & 100 & 533,6 & 100 & 912,35 & 100 \\
\hline
\end{tabular}

Fuente: Elaboración propia a partir del padrón de viñas de 1777. Archivo Nacional de Chile, Capitanía General, volumen 353, fojas 119-158. 
Los microproductores eran el grupo más numeroso. Integraban este segmento 246 aguardenteros (76\%), y elaboraban 315 arrobas de producto (34\%). Tres cuartos de los productores elaboraban un tercio del aguardiente total. Cada uno de ellos obtenía escasa cantidad de ese producto. Algunos producían una o dos arrobas; pero muchos de ellos apenas destilaban unos pocos cuartillos de aguardiente. Naturalmente, el valor comercial de cantidades tan ínfimas era casi despreciable. El objetivo de estos productores era, fundamentalmente, el consumo doméstico y hacendal, aunque también les quedaba una parte para dedicar al comercio, sobre todo los que lograban obtener más de una o dos arrobas de aguardiente. Aunque la rentabilidad comercial de esta actividad fuese acotada, lo interesante era la experiencia, la capacidad de los viticultores por transitar los complejos caminos de la elaboración de un destilado, y de resolver los problemas de envasado, conservación, transporte y comercialización. Sobre la base de estas experiencias, se abrían grandes posibilidades de proyección para este grupo, a la vez que reflejaba la presencia de la cultura del trabajo en estas localidades. Desde el punto de vista territorial, los microproductores eran el grupo mayoritario en los tres corregimientos, sobre todo en Cauquenes (85\%) y Colchagua (82\%); en cambio, en Quillota su presencia era notablemente menor que en las anteriores $(58 \%)$.

Los productores pequeños elaboraban entre tres y diez arrobas de aguardiente. Este grupo estaba compuesto por 59 productores (18\%) y obtenía 320 arrobas (35\%). Se trata de un sector más equilibrado que el anterior, pues el $20 \%$ de los productores obtenían un tercio del aguardiente total. Este grupo estaba más conectado con el mercado; en algunos casos vendía al por mayor a las grandes haciendas o a las pulperías; en otras oportunidades los mismos productores podían vender al público en sus casas, ramadas o pulperías; también podían transportar sus aguardientes a mercados más distantes en recuas de mulas. Si se compara la presencia de este grupo entre los tres corregimientos, se detecta el liderazgo de Quillota; 29 productores locales se ubicaba dentro de este grupo, lo cual representaba más de un tercio (35\%). En cambio, la incidencia de los pequeños productores era menor tanto en Colchagua (11\%) como en Cauquenes (15\%).

Los productores medianos se distinguían por obtener entre 11 y 26 arrobas de aguardiente por cosecha. Integraban este grupo 17 empresarios (5\%) y elaboraba 207 arrobas de aguardiente por ańo (22\%). Se encontraban solamente en Quillota y Colchagua. En Cauquenes, en cambio, no existía ninguno; todos eran micro o pequeños productores. Los productores medianos eran el grupo más dinámico y productivo.

Por último, la categoría de "productor grande" solo tenía un participante: la Hacienda Choapa. Esta sola propiedad elaboraba 70 arrobas de aguardiente, lo cual representaba el $24 \%$ de la producción total de esa provincia, y el $7 \%$ de la región general formada por los tres corregimientos. 
Lo más relevante del sistema, era la notable fragmentación del aparato productivo. No había monopolios ni capacidad de control por parte de las grandes haciendas sobre los micro y pequeños productores. Estos elaboraban el $70 \%$ del aguardiente total en el área estudiada. En cambio, los medianos y grandes, apenas llegaban a elaborar el 30\%, con lo cual no podían imponer precios ni condiciones. El poder dentro de este negocio estaba fragmentado entre cientos de pequeños productores.

\section{FORMAS DE ELABORAR EL AGUARDIENTE: VIÑAS Y EQUIPAMIENTO}

Uno de los elementos que, según Hernán Cortés, estaba pendiente de investigación, es la forma concreta de elaborar el aguardiente, es decir, el equipamiento y la relación con las uvas. En este sentido, el Padrón no entrega mayores detalles, pero sí los testamentos, inventarios de bienes y demás documentos notariales y judiciales producidos por los productores registrados en ese registro.

¿Qué proporción de la uva producida se dedicaba a producir aguardiente? Para conocer este dato, es importante tener en cuenta el rendimiento de la fruta, la cantidad de plantas cultivadas y de aguardiente elaborado. El Padrón refiere los datos del tercer punto; los testamentos y registros notariales se ocupan del segundo; y la historia económica colonial despeja la primera incógnita.

Los métodos de producción vigentes en Chile establecían que, cada 1000 cepas se obtenían 100 arrobas de mosto; si este se dedicaba íntegramente a destilación, se obtenían 20 arrobas de aguardiente. De todos modos, los productores de las regiones estudiadas elaboraron cantidades muy inferiores. El foco del interés productivo estaba puesto en el vino y no en el aguardiente. El mosto se dedicaba íntegramente a fermentación para obtener vino y luego comercializarlo, sin destilarlo. El aguardiente se obtenía del orujo y las borras.

No había una correlación fija entre cantidad de plantas y volumen de aguardiente elaborado. Unas veces se producía más y otras menos; pero lo más habitual era obtener una arroba de aguardiente cada 2000 plantas de vińa. Como solo se usaban borras y orujos para destilar aguardiente, la tendencia general muestra que a partir de una vińa de 2000 cepas, se elaboraban 200 arrobas de mosto y una arroba de aguardiente. A pesar de representar una proporción tan pequeńa dentro de la industria, los productores se preocuparon por disponer de instalaciones y equipamiento específico para elaborar aguardiente. Algunos establecimientos contaban con bodegas exclusivas para esta actividad, o bien, con corrales de alambiques. Igual que los edificios dedicados al vino, las bodegas de aguardiente eran construcciones con muros de adobe, techos de teja y puertas

y ventana de madera. En su interior estaban las pailas, los cañones y tinajas de 
aguardiente. Pailas y cañones eran de cobre, metal muy abundante en Chile, aunque la hija de un estanciero colchagüino nacida por 1595 , entre sus bienes tenía una alquitara de plomo $^{21}$. Los cañones tenían una longitud de entre 1 1/2 y $21 / 2$ varas. Las pailas tenían distintas medidas y servían para calentar el zumo obtenido de orujos y borras. La demanda de todos estos pequeños productores de aguardiente significó un estímulo para la manufactura de cobre.

\section{¿QUIÉNES ERAN LOS PRODUCTORES DE AGUARDIENTE?}

Si cada productor no elaboraba más de tres arrobas de aguardiente por año, en promedio, es evidente que esta no era su actividad principal sino un complemento de otras tareas. Por lo tanto, conviene identificar con mayor claridad el perfil de estos aguardenteros a través de una mirada de conjunto de sus restantes actividades y su extracción social y económica. La idea es identificar quién era el productor de aguardiente.

Al realizar el cruce del Padrón con los registros judiciales y notariales, fue posible obtener datos sociales y económicos de una parte de los empadronados. Se trata de una tarea parcial, porque la mayoría de los aguardenteros no se pudieron localizar. En algunos casos aparecieron homónimos que, por no coincidir algunas características de tiempo y espacio, debieron descartarse. Finalmente se logró conformar un corpus documental equivalente al 10\% aproximadamente del recuento. Y sobre esa base, se ha podido trazar un perfil tentativo de los productores.

¿Cuál era la extracción social de los aguardenteros? ¿Eran terratenientes o pequeños propietarios? ¿Eran nobles o plebeyos? ¿Cuál era la importancia de la viticultura dentro de sus actividades? Con estas preguntas se abordaron los datos, y se llegó a respuestas muy amplias por la heterogeneidad de los participantes en esta actividad.

La nobleza se interesó en las viñas y el aguardiente. Como se sabe, muy pocos nobles titulados había en el Cono Sur de América, por lo tanto, se trata de un tema un tanto raro. Pero justamente, algunos de ellos se interesaron en el mundo de la vid y el vino. Fue el caso del Marqués de la Pica, título otorgado el 18 de julio de 1684 por el rey Carlos II al maestre de campo don Francisco Bravo de Saravia y Ovalle, alcalde de Santiago, por los servicios prestados en la Guerra de Arauco. Este fue el primer Marqués de la Pica (1684-1703), y fue sucedido por doña Marcela Bravo de Saravia (1703-1752). Esta noble familia se interesó en la actividad vitivinícola, según se reflejó en las viñas que cultivó en los alrededores de Santiago ${ }^{22}$. También participó en esta actividad en el corregimiento de Quillota, fundamentalmente con las viñas de Illapel, en el marco de su mayorazgo.

\footnotetext{
${ }^{21}$ Muñoz (2011: 181).

${ }^{22}$ Villar Letelier, 2006.
} 
El mayorazgo de la Pica fue fundado el 2 de noviembre de 1728 por la marquesa de la Pica en beneficio de su hijo primogénito don Agustín Bravo de Saravia Andía Irarrázabal. Los bienes tenían un valor de 37.000 pesos, e incluían la casa principal de Santiago, la hacienda ganadera de Pullahue (La Ligua) y la hacienda Illapel, con su trapiche de oro $^{23}$. Las principales fuentes de riqueza del mayorazgo eran la ganadería y la minería; pero también hubo interés en la viticultura: el Padrón registró al marqués actual como propietario de dos viñas en La Ligua y una en Illapel, la cual producía 16 arrobas de aguardiente.

Los grandes comerciantes también se vieron atraídos por esta actividad. Se trata de personajes cuya actividad principal se había generado en el intercambio comercial, y más tarde, diversificaron inversiones hasta conectarse con el mundo de las viñas. Fue el caso de don José Basilio de Rojas Corbalán, aunque descendiente de grandes estancieros, se desempeñó en esta más rentable actividad. En el Padrón figura con una viña en Limache, corregimiento de Quillota, en la cual producía una arroba de aguardiente. Natural de Colchagua, Rojas se dedicó desde la adolescencia a la vida comercial. Tenía entre 14 y 16 años cuando comenzó en esta actividad. Logró construir extensas redes, viajó varias veces a Lima, y se transformó en comerciante experto. Su centro de operaciones se hallaba en Santiago, pero se interesó en invertir en las zonas rurales cercanas. En este contexto adquirió varias estancias, San Diego de la Palma, Peńaflor, Tango y Mallarauco, esta en el punto de encuentro entre los corregimientos de Melipilla y Quillota. Como se ha señalado, el Padrón lo registró con una pequeña producción en Limache, localidad cercana a la mencionada estancia. Pero su mayor logro, como es dable suponer, fue la fundación de un mayorazgo a favor de una sobrina. Testó el 20 de junio de $1781^{24}$.

El mundo de los aventureros también se sintió convocado a participar de la viticultura y la elaboración de vinos y aguardientes. Se trata de personalidades extrañas y transgresoras, que vivían en los márgenes de la ley, en las zonas grises de la legalidad, amantes del riesgo y las fuertes emociones. Podían construir una posición expectante, generar confianza, y luego defraudarla y huir en forma irresponsable, para luego regresar y poner en marcha nuevos emprendimientos, para el asombro de todos. Este fue el caso de Juan Antonio Mendoza que se desplazaba por toda la Zona Central de Chile, de Quillota a Cauquenes. En Quillota figura con una viña y una producción de dos arrobas de aguardiente; en Cauquenes se dedicó al negocio de los diezmos. Al realizar sus actividades en distintos lugares, lograba endeudarse primero y burlar a los acreedores después. Los damnificados de sus negocios iniciaron un proceso judicial que terminó con orden de ejecución de bienes para recuperar el capital. Se levantó entonces, el 7 de enero de 1791, un inventario de

\footnotetext{
${ }^{23}$ AN, Fondo Escribanos de Santiago (FES), 491, 202.

${ }^{24}$ AN, FES, 824, 102.
} 
sus bienes para rematarlos. Se completaron tres libros de a cuartilla con las cuentas, pero solo se pudo consignar deudas por fanegas de trigo y animales ${ }^{25}$.

Junto con los aventureros, la industria de la vid y el vino convocó también a sectores más modestos, que avanzaron lentamente a partir de su propio trabajo personal. Como ejemplos se pueden citar los casos de doña Rosa Guzmán, don José Rojas, don José Guerrero y don Tomás Arriagada. Doña Rosa Guzmán era hija natural de don José Guzmán, no recibió propiedades en herencia sino un legado paterno de 250 pesos, que se le adjudicaron en la testamentaría el 3 de noviembre de 1802 en San Fernando ${ }^{26}$. A pesar de los problemas derivados de su origen, logró abrirse camino y en 1777 figura como propietaria de una viña en Cauquenes y productora de una arroba de aguardiente. Algo parecido ocurrió con el matrimonio formado por don José Rojas Hidalgo y doña María Antonia Serrano. En el momento de casarse, ninguno de los dos aportó bienes al matrimonio. Gracias a la industria y el trabajo de ella, lograron generar una situación de relativa prosperidad, lo cual se reflejó en la compra de la estancia de Puangue, en Melipilla, según declara él en el testamento del 15 de septiembre de 1792, y ambos en uno mutuo del 23 de marzo de $1797^{27}$. Además en el barrio de la Chimba, calle Recoleta, también adquirieron una finca. El Padrón los registró con una viña en Limache, que producía dos arrobas y media de aguardiente. Don José Guerrero también puede asimilarse a este grupo; el registro de 1777 lo situó con una viña en Quillota y una arroba y media de aguardiente. Sus bienes se limitaban a un solar con lo edificado y plantado, incluyendo su casa, su viña y sus frutales. Por su parte, don Tomás Arriagada comenzó su vida económicamente activa con pocos recursos. $\mathrm{Su}$ mujer no aportó bienes dotales al casamiento, mientras que él poseía un majuelo de viña con árboles. Después de una vida de trabajo, logró formar una posición relativamente próspera: su vińa tenía 2828 plantas; la bodega era un edificio de 21 por siete varas tres cuartos, con 16 tinajas, tres pailas y cañón para destilar aguardiente. El inventario de sus bienes, en 1790, registró también entre 50 y 60 arrobas de vino. Tenía un molino de pan, ropa, dos esclavos y ajuar de la casa, que incluía los aderezos de mate con bombilla y mancerina de plata ${ }^{28}$. El Padrón registró ocho sujetos de esta familia, y la viuda de otro, curiosamente su fundador, nacido en el siglo XVI, ya había tenido viñas en el valle de Teno.

Mayor presencia tuvo otro sector social privilegiado, más amplio en América Latina en general y en Chile en particular: el grupo de los terratenientes. Buena parte de los productores de aguardiente eran propietarios de extensiones más

\footnotetext{
${ }^{25}$ AN, Fondo Judiciales de Cauquenes(FJC), 7, 9, 1- $22 \mathrm{v}$.

${ }^{26}$ AN, Fondo Judiciales de San Fernando (FJSF), 39, 3, 1 - 5.

${ }^{27}$ AN, FES, 873, 316 y 926, 278.

${ }^{28}$ AN, FJSF, 19, 2, $1-28 \mathrm{v}$.
} 
amplias de terrenos, a veces tierras de cultivo; en otros casos se trataba de meros campos incultos en zona de montaña; o bien, mezclas de ambas modalidades. Los casos de don Andrés Lobo, doña Josefa Huerta, don Fernando Norambuena, doña María Prado, Nicolás de la Cerda y don Bernardo Valdebenito.

Don Andrés Lobo, presente en el Padrón como propietario de una viña y productor de una arroba de aguardiente, era un terrateniente: junto con un hermano poseían la estancia San Antonio de Tichaumo, de 300 cuadras de pan llevar ${ }^{29}$. Por su parte, dońa Josefa Huerta, productora de dos arrobas dos cuartillos en el Padrón, fue heredera de parte de 300 cuadras de la estancia La Cueva, doctrina de Rosario, 16 de marzo de $1814^{30}$. A su vez, don Fernando Norambuena, productor de una arroba de aguardiente en el Padrón, era uno de los herederos de una propiedad de 900 cuadras de tierra. Por su parte, doña María Prado, heredera junto con sus hermanos de la estancia de Curacaví, aparece en el Padrón como propietaria de la única que existía entonces en Casablanca. Parecido fue el caso del maestre de campo Nicolás de la Cerda, propietario de la estancia de Chicauma, entre otros bienes que incluían varios esclavos. El Padrón lo registró como propietario de tres vińas en La Ligua y productor de ocho arrobas de aguardiente. Don Bernardo Valdebenito poseía cerca de 2000 cuadras de tierra, de las cuales 900 de montańa en El Baúl, 100 en los Pochemas, 166 de pan llevar en Quillay y 834 de la estancia Curanipe. Sus principales actividades eran el cultivo de trigo, la elaboración de harina en el molino, la producción ganadera (250 cabezas) y textil (tenía un telar). En Curanipe tenía una casa de 30 por seis varas con un corredor de dos varas. En la villa de Chanco tenía otra casa de teja con un sitio de 24 varas, testó el 26 de septiembre de $1804^{31}$. Más detalles se entregan en el Cuadro III:

\section{Cuadro III}

Productores de aguardiente - terratenientes

\begin{tabular}{|l|l|l|}
\hline Nombre & Padrón 1777 & Observaciones \\
\hline Andrés Lobo & $\begin{array}{l}1 \text { viña 1 @ } \\
\text { Cauquenes }\end{array}$ & $\begin{array}{l}\text { Estancia San Antonio de Tichaumo (300 } \\
\text { cuadras) }\end{array}$ \\
\hline Josefa Huerta & $\begin{array}{l}1 \text { viña } 2 @ \\
\text { Cauquenes }\end{array}$ & Estancia La Cueva (300 cuadras) \\
\hline Fernando Norambuena & $\begin{array}{l}1 \text { viña 1 @ } \\
\text { Cauquenes }\end{array}$ & 900 cuadras \\
\hline
\end{tabular}

\footnotetext{
${ }^{29}$ Tras la muerte de su hermano, Andrés Lobo vendió la estancia a doña Ignacia Martínez. Santiago, 4 de agosto de 1755. AN, FES, 757, $265 \mathrm{v}$.

${ }^{30}$ AN, FJSF, 39, 5, 1- $8 \mathrm{v}$.

${ }^{31}$ AN, FJC, 24, 12, 1- $32 \mathrm{v}$.
} 


\begin{tabular}{|c|c|c|}
\hline $\begin{array}{l}\text { Juan Francisco López y } \\
\text { Sánchez }\end{array}$ & $\begin{array}{l}1 \text { viña } 3 @ \\
\text { Cauquenes }\end{array}$ & 2000 cuadras en Nilahue \\
\hline Luis Molina & $\begin{array}{l}1 \text { viña } 2 @ \\
\text { Cauquenes }\end{array}$ & 600 cuadras en Maitén Amarillo \\
\hline Juan López & $\begin{array}{l}1 \text { vińa } 3 @ \\
\text { Cauquenes }\end{array}$ & 200 cuadras en paraje Dangil \\
\hline Bernardo Valdebenito & & 2000 cuadras \\
\hline María Prado & $\begin{array}{l}1 \text { vińa 3,5 @ } \\
\text { Casablanca }\end{array}$ & Estancia de Curacaví \\
\hline Petronila Miranda & $\begin{array}{l}1 \text { viña } 8 @ \\
\text { San Fernando }\end{array}$ & Estancia Santa Gertrudis ( 492 cuadras) \\
\hline Nicolás de la Cerda & $\begin{array}{l}3 \text { viñas } 8 @ \\
\text { La Ligua }\end{array}$ & Estancia Chicauma \\
\hline Lucas Vásquez & $\begin{array}{l}1 \text { viña 11/2@ @ } \\
\text { Quillota }\end{array}$ & Estancia El Coliguay \\
\hline Juan Vásquez & $\begin{array}{l}1 \text { viña } 2 @ \\
\text { Quillota }\end{array}$ & Una estancia de 1000 cuadras \\
\hline
\end{tabular}

Fuente: Elaboración propia a partir del padrón de viñas de 1777. Archivo Nacional de Chile, Capitanía General, volumen 353, fojas 119-158. Fondos judiciales y notariales.

El Cuadro III muestra el nexo que había entre algunos viticultores y productores de aguardiente, con la clase tradicional de los terratenientes. En muchos casos, el cultivo de la viña y la elaboración de vinos y aguardientes era una tarea secundaria dentro de una propiedad orientada fundamentalmente a la siembra o la ganadería.

Otro sujeto histórico involucrado en esta actividad era el agroindustrial. Integraban este grupo aquellos que tenían buena parte de sus energías focalizadas en la producción de manufacturas de origen agropecuario; cultivaban vińas y frutales para elaborar vino, aguardiente y conservas; también tenían molinos, curtiembres y otras instalaciones para elaborar sus productos agroindustriales y dedicarlos principalmente a la comercialización. Si el sector terrateniente se orientaba a la cultura de la renta, el sector agroindustrial se inclinaba a la cultura del trabajo. Alejo Sánchez, doña Luisa de Hevia, don Manuel del Campo y Fermín Alvear formaban parte de este grupo.

Las viñas de don Alejo Sánchez tenían 1950 plantas, y su bodega contaba con 34 arrobas de vasija, además de lagar y cañón de destilación. Tenía tres propiedades que, en conjunto, reunían 110 cuadras de tierras; en el casco de su pequeña estancia tenía un huerto de frutales donde cultivaba 131 plantas, incluyendo carozos (durazneros y guindos), pomáceas (perales, manzanos y membrilleros) y otros (nogales, higueras, parrones), la partición de sus bienes se efectuó en La Lagunilla, Cauquenes, el 23 de agosto de $1793^{32}$.

${ }^{32}$ AN, FJC, 11, 9, 1- $11 \mathrm{v}$. 
Doña Luisa de Hevia, empadronada viuda en 1778, tenía una viña con 1170 cepas, 43 arrobas de vasija en la bodega, tres lagares (uno de cuero), dos pilones y 97 plantas frutales entre carozos (durazneros y albaricoques), pomáceas (manzanos y perales), cítricos (dos naranjos), y otros (seis nogales, tres olivos, una higuera). La bodega era de nueve y media por cinco y media varas; la puerta tenía armellas de fierro. Sus particiones se efectuaron en San Fernando el 13 de septiembre de $1794^{33}$.

Don Manuel del Campo Léon, hijo de un francés que también fue productor de vino y aguardiente, además de la estancia de Panquehue tenía una hijuela en la estancia de Malloa y casa en la villa de San Fernando. Su viña contaba con 10.000 plantas; la bodega tenía tres enfriaderas de 22 arrobas, junto con 39 tinajas con 325 arrobas de capacidad. En el inventario se registraron $1831 / 2$ arrobas de "vino alińado de buena calidad". Para elaborar aguardiente tenía dos cañones, uno de dos varas y el otro de dos y media. Las construcciones incluían una pieza de teja, otra pieza con corredor de horcones:

Un cañón que sirve de bodega con 18 varas de largo y media de ancho con una puerta de dos manos de dos varas y cuarto de ancho con 20 vigas de madera de canelo sus correspondientes tijerales clavados con clavos de pato su corredor con 12 horcones de espino y 28 viguetas, todo el corredor se halla algo maltratado; un rancho para lagar, un rancho que sirve de casona, un rancho para granero y otro rancho viejo. Sus particiones se efectuaron el 28 de septiembre de $1789^{34}$.

La viña de Fermín Alvear contaba con 9536 cepas; sus bodegas tenían una capacidad de vasija de 231 3/4 arrobas; para destilar aguardiente tenía una paila y un cańón de cobre de una y media vara. Vivía en una modesta casa de paredes de adobe y techo de tejas, de 22 varas de largo por siete de ancho. Los notarios detectaron también la presencia de 30 arrobas de vino bueno. Su hacienda tenía esclavos, diversos animales y una curtiduría, según se contabilizó en el inventario de sus bienes, Cauquenes, 24 de septiembre de $1791^{35}$.

El grupo de los agroindustriales se traslapaba, a veces, con el de los terratenientes. En algunos casos, este sector se orientó a la vitivinicultura con tal nivel de intensidad, que esta tarea pasó a formar parte importante dentro de su dinámica. Los casos de dońa Petronila Miranda, don Bernardo Valdebenito, don Agustín Gamboa y dońa Francisca Donoso son buenos ejemplos.

\footnotetext{
${ }^{33}$ AN, FJSF, 31, 3, 1- $14 \mathrm{v}$.

${ }^{34}$ AN, FJSF, 26, 4, 1- 21.

${ }^{35}$ AN, FJC, 9, 1, 1- $34 \mathrm{v}$.
} 
Doña Petronila Miranda Arce, viuda de don Ignacio Chacón Silva, era propietaria de la hacienda Santa Gertrudis, junto al río Tinguiririca. El terreno comprendía 492 cuadras con sus casas y establecimientos pecuarios, agrícolas y agroindustriales. Entre las plantas de vid se incluía un parral de uva negra, tres pies de uva mollar y dos pies de uva de Italia (moscatel de Alejandría). También había 15 pies de parral, un majuelo de 158 cepas, bien tratado, una vińa nueva de 1790 plantas con cerco de tapia, y una vińa vieja de una cuadra y tres cuartos, tan aparronada que no se pudo contar. En total, se cultivaban aproximadamente 5000 plantas. La mayor parte de la uva se dedicaba a elaborar vino. La bodega contaba con 21 tinajas para conservar vino. Allí se registraron 30 arrobas de vino de la cosecha anterior, otras 30 arrobas de vino aliñado de la última cosecha y dos arrobas de mosto sin aliño. Para pisar la uva había dos lagares de dos cueros cada uno, una zaranda con su marco y su rejilla de látigo, y 25 pilones, dos de ellos que servían de piqueras. La hacienda también tenía un galpón dedicado exclusivamente a la producción de aguardiente. Estaba equipado con dos cañones de destilación y dos tinajas de aguardiente. Sus inventarios se verificaron el 19 de abril de $1784^{36}$.

Don Bernardo Valdebenito era un terrateniente con cerca de 2000 cuadras, como se ha seńalado oportunamente. Pero parte importante de su energía se canalizaba hacia la viticultura. Cultivaba 549 plantas de viña frutal en la estancia de Curanipe y una vińa de 4550 plantas en Itata, cerca de Corońe. Sus bodegas tenían cuatro tinajas con 23 arrobas de capacidad; dos botijas; un barril de madera, una botijuela vidriada, un vasito de cristal, dos botellas de vidrio. Testó el 26 de setiembre de $1804^{37}$.

Don Agustín de Gamboa Gajardo, anotado en el valle de Teno con dos arrobas anuales de aguardiente. Además de trabajar las tierras y viña heredadas, las actividades de la familia abarcaban molinería y curtiembre. Con dońa Rosa Torrealba González de Medina, su mujer, compraron las estancias de Rauco y San Lorenzo al comisario don Domingo de la Arriagada en 6.600 pesos, plantaron en ellas una vińa, edificaron casas, hicieron una acequia y cercos, siendo por cierto, la ganadería una de las actividades principales. Para sus operaciones solía recurrir a los sistemas crediticios existentes en la época ${ }^{38}$.

Por su parte doña Francisca Donoso Gutiérrez, sacaba cuatro arrobas en Colchagua, su familia había sido dueña de la estancia Santa Cruz de Unco. En 1786 fue empadronada en la jurisdicción de Colchagua como noble y viuda. Había sido casada con el guipuzcoano don Sebastián de Estolaza Gorostiza, dueños de extensas estancias, entre las cuales está Caylligüe ${ }^{39}$.

\footnotetext{
${ }^{36}$ AN, FJSF, 21, 7, 1- $10 \mathrm{v}$.

${ }^{37}$ AN, FJC, 24, 12.

${ }^{38}$ AN, FJSF 29 6, 1 y ss.

${ }^{39}$ AN, FES, 137, 190.
} 


\section{CONCLUSIÓN}

El Padrón de 1777 ha permitido detectar con mayor claridad algunos aspectos de la producción de aguardientes en la Zona Central de Chile en el siglo XVIII. En primer lugar, se ha identificado una tendencia general de los viticultores a destilar aguardiente como parte de su tarea de elaboración de los productos de sus viñas. La mayor parte de la uva se dedicaba al vino, pero el aguardiente también representaba una parte significativa. Por lo tanto, la investigación permite detectar el carácter universal que tenía la práctica de la destilación en el mundo de los vińedos.

El segundo aspecto importante se refiere a la forma de obtener ese aguardiente. En los tres corregimientos estudiados, todos ellos de la Zona Central de Chile, la destilación se realizaba a partir del orujo y las borras. De esta manera se podía obtener un aguardiente de segunda categoría, llamado también grapa. Esta práctica difería claramente de los usos de la Zona Norte del país (sobre todo entre Copiapó y los Valles del Elqui y Limarí), donde se elaboraba aguardiente de primera calidad, a partir de la destilación del vino. Este producto se llamaría Pisco.

El cruce de las listas de productores con los datos judiciales y notariales ha permitido conocer mejor la extracción socioeconómica de los productores de aguardiente en la Zona Central de Chile. Nobles conservadores y audaces comerciantes; pobres campesinos y acaudalados terratenientes; tal vez algunos aventureros y severos trabajadores del campo vivieron experiencias diametralmente opuestas; sus valores y estilos de vida podían presentar diferencias radicales. Sin embargo, tuvieron algo en común en aquel chileno siglo XVIII: se sintieron atraídos, como muchos de sus antepasados de los dos siglos anteriores, por el mundo de la vid.

La viña, el vino y el aguardiente tuvieron una capacidad de convocatoria notable en el pueblo chileno. Se acercaron a ese mundo sectores cuyas tareas principales pasaban por ámbitos muy diversos: algunos tenían su medio de vida en la minería; otros, en la ganadería, el comercio, entre otros. Pero, a pesar de ello, se produjo como una convergencia hacia un punto de unidad cultural. Muchos de estos sujetos históricos aceptaron la llamada de la vińa y coincidieron en construir un paisaje rural y periurbano en torno a estos elementos.

El Padrón de 1777 entrega algunas claves para detectar un proceso que, hasta ahora, había permanecido poco visible. En los corregimientos periféricos del Reino de Chile, donde las ciudades eran apenas villas incipientes con pocos vecinos, y la población estaba mayoritariamente distribuida en el campo, aislada y sin medios de transporte disponibles, floreció una temprana industria vitivinícola de pequeños productores de aguardiente.

Sobre un total de 353 viñas, el $90 \%$ de los propietarios se interesaron por elaborar aguardiente para aprovechar los orujos y borras. No era la actividad 
principal de estas viñas, pues su objetivo central era elaborar vino. Usualmente, los productores dedicaban el $97,5 \%$ de la uva al vino y sólo el $2,5 \%$ al aguardiente. Este brindaba la oportunidad de un mejor aprovechamiento de las materias primas que, de otro modo, se perdería. Al esforzarse en utilizar los orujos para obtener aguardiente, estos viticultores lograban bajar sus costos de producción y facilitar la rentabilidad de la industria.

La importancia de esta actividad no radica en la calidad del producto; tal como señaló Claudio Gay, los aguardientes elaborados a partir de orujos y borras, no eran bebidas agradables ni en gusto ni en perfume. Pero sí fue importante desde el punto de vista económico y social. En lo económico, el aguardiente significó un ingreso extra, lo cual contribuyó a facilitar la sustentabilidad económica de los emprendimientos rurales. En lo social, la práctica de utilizar los orujos y borras para elaborar aguardiente constituyó una costumbre que focalizó energías y atención en el mundo productivo; los viticultores aprendieron técnicas de destilación, conservación, envase, transporte y comercialización de un producto comercial. Y a través del dominio de estas técnicas, lograron fortalecer la cultura del trabajo y a la vez, consolidaron el tradicional lazo entre los chilenos, la vińa, el vino y el aguardiente.

\section{REFERENCIAS}

Aballay y Meglioli, Gladys. La corona demanda tributa. El léxico impositivo de la época colonial para la región de Cuyo. San Juan: Editorial de la Universidad de San Juan, 2008.

Amaral, Samuel. "Comercio libre y economías regionales. San Juan y Mendoza, 1780-1820", Jahrbuch für Geschishte von Staat, Wirtschaftund Gesellschaft Lateinamerikas 27 BöhlauVerlagKölnWien (1990): 1-67.

Bennett, Norman. That indispensable article: Brandy and Port Wine 1605-1908. Porto, GEHVD, 2005.

Braudel, Fernand. Bebidas y excitantes. Madrid: Alianza Editorial S. A., 1994.

Cobos, María Teresa. La división politico-administrativa de Chile, 1541-1811. Santiago de Chile: Universidad Católica de Valparaíso, 1989.

Coria, Luis Alberto. Evolución económica de Mendoza durante la época colonial. Mendoza: UNC, FCE, 1989. 
Corona Páez, Sergio. La vitivinicultura en el pueblo de Santa María de las Parras. Producción de vinos, vinagres y aguardientes bajo el paradigma andaluz (siglos XVII y XVIII). Torreón: Ayuntamiento de Torreón, 2004.

Cortés Olivares, Hernán. "El origen, producción y comercio del pisco chileno, 1546-1931”, Universum 20/2 (2005): 42-81.

Cuevas, José de las. Historia apasionada del Brandy de Jerez. España: Geribel, 2003.

Del Pozo, José. Historia del vino chileno. Santiago de Chile: Universitaria, 1999.

Drago Rojas, Guillermo. Historia de Rancagua. III tomos. 2a edición. Rancagua: Círculo Literario Fénix, 1994.

Donoso, Ricardo. El marqués de Osorno, don Ambrosio O'Higgins 1720-1801. Santiago de Chile: Universidad de Chile, 1941.

Gay, Claudio. 1855. Historia fisica y politica de Chile. Tomo II Agricultura. París: Casa del Autor/Chile: Museo de Historia Natural de Santiago. Edición moderna consultada: Santiago de Chile: ICIRA, 1973.

Huerta Vallejos, Lorenzo. "Historia de la producción de vinos y pisco en el Perú", Universum 19/2 (2004): 44-61.

Lacoste, Pablo. "Carretas y transporte terrestre bioceánico: la ruta Buenos AiresMendoza en el siglo XVIII”, Estudios Iberoamericanos 31/1 (2005a): 7-34.

Lacoste, Pablo. "El tropero y los orígenes de la burguesía en el cono sur de América colonial: Mendoza, siglo XVIII", Estudios Iberoamericanos 31/2 (2005): 177-206.

López Chávez, Celia. "Con la cruz y con el aguardiente: La empresa vitivinícola jesuita en el San Juan colonial”, Universum 20/2 (2005): 82-107.

Mayo, Carlos (Ed.). Vivir en la frontera. La casa, la dieta, la pulpería, la escuela (1770-1870). Buenos Aires: Biblos, 2000.

Mayo, Carlos (Dir.). Pulperos y pulperías de Buenos Aires (1740-1830). Buenos Aires: Biblos, 2000. 
Mayorga Zuñiga, Marcelo. "La tradición de la producción artesanal de aguardiente en Cauquenes, 1771-1821”, Revista RIVAR 1/2 (2014): 55-70.

Mellafe, Rolando y Salinas Meza, René. Sociedad y Población en la Formación de Chile Actual. La Ligua, 1700-1850. Santiago de Chile: Universidad de Chile, 1985.

Muñoz, Juan Guillermo. Don Melchor Jufré del Águila. Biografía, obra y descendencia. Santiago de Chile, 2011.

Muñoz, Juan Guillermo. "Las viñas y el vino de Colchagua en el siglo XVII", Boletín de la Academia Chilena de la Historia LXVII/110 (200): 165-204.

Pinto, Sonia. Vias y medios de comunicación en Chile durante el siglo XVIII: El camino Santiago Valparaiso y su tráfico. Santiago de Chile: Universidad de Chile, 1976.

Premat, Estela. "La bodega mendocina de los siglos XVII y XVIII”, Universum 22/1 (2007): 118-135.

Rice, Prudence. Vintage Moquegua. History, wine and archaeologicy on a colonial Peruvian periphery. Austin, Texas: University Press, 2012.

Rivera Medina, Ana María. "La infraestructura para la elaboración de caldos: Bodegas y lagares en San Juan de la Frontera (s. XVII-XVIII)", Universum 22/1 (2007): 136-151.

Silva, Hernán Asdrúbal. "El vino y el aguardiente en la Buenos Aires de la primera mitad del siglo XVIII". VI Congreso Internacional de Historia de América. Buenos Aires: Academia Nacional de la Historia, 1982.

Soldi, Ana María. "La vid y el vino en la costa central del Perú, siglos XVI y XVII", Universum 21/2 (2006): 42-61.

Villar Letelier, Virginia. "De la viña de Cáceres a la del Marqués de la Pica, pasando por la de Saravia. A extramuros de Santiago", Revista virtual Palimpsesto 6 (2006). Disponible en: http:www.palimpsestousach.cl 
